\title{
Perceived Discrimination, Depression, and the Role of Perceived Social Support as an Effect Modifier in Korean Young Adults
}

\author{
Kwanghyun Kim', Sun Jae Jung ${ }^{1,2}$, So Mi Jemma Cho ${ }^{3}$, Ji Hye Park³, Hyeon Chang Kim \\ ${ }^{1}$ Department of Preventive Medicine, Yonsei University College of Medicine, Seoul, Korea; ${ }^{2}$ Department of Epidemiology, Harvard T. H. Chan School \\ of Public Health, Boston, MA, USA; ${ }^{3}$ Department of Public Health, Yonsei University Graduate School, Seoul, Korea
}

Objectives: The relationships among discrimination, social support, and mental health have mostly been studied in minorities, and relevant studies in the general population are lacking. We aimed to investigate associations between discrimination and depressive symptoms in Korean non-minority young adults, considering the role of social support.

Methods: In total, 372 participants who completed the psychological examinations conducted in the third wave of the Jangseong High School Cohort study were included. We used the Everyday Discrimination Scale to evaluate perceived discrimination and the Beck Depression Inventory-II to measure depressive symptoms. Social support was measured by the Multidimensional Scale of Perceived Social Support. Multivariate linear regression was conducted to investigate associations between discrimination and depression, along with the effect modification of social support. We stratified the population by gender to investigate gender differences.

Results: Perceived discrimination was significantly associated with depressive symptoms ( $\beta=0.736, p<0.001$ ), and social support was negatively associated with depression $(\beta=-0.245, p<0.001)$. In men, support from friends was the most influential factor $(\beta=-0.631$, $p=0.011)$, but no significant effect modification was found. In women, support from family was the most influential factor $(\beta=-0.440$, $p=0.010$ ), and women with higher familial support showed a significantly diminished association between discrimination and depression, unlike those with lower family support.

Conclusions: Discrimination perceived by individuals can lead to depressive symptoms in Korean young adults, and this relationship can may differ by gender and social support status.

Key words: Discrimination, Depression, Social support, Korea

\section{INTRODUCTION}

The negative effects of discrimination on health are now

Received: May 15, 2019 Accepted: October 8, 2019

Corresponding author: Sun Jae Jung, MD, PhD Department of Preventive Medicine, Yonsei University College of Medicine, 50 Yonsei-ro, Seodaemun-gu, Seoul 03722, Korea E-mail: sunjaejung@yuhs.ac

This is an Open Access article distributed under the terms of the Creative Commons Attribution Non-Commercial License (http://creativecommons.org/licenses/by$\mathrm{nc} / 4.0 /$ ) which permits unrestricted non-commercial use, distribution, and reproduction in any medium, provided the original work is properly cited. well established. Several studies have reported that discrimination is associated with poor health outcomes, including obesity [1], depression [2], and suicidal ideation [3].

Most previous studies exploring the health effects of discrimination have focused on "minority populations," such as immigrants [4], ethnic minorities [5], and sexual minorities [6], as they are frequently exposed to discrimination. However, members of the general community could also experience 
discrimination or unjust treatment due to gender or socioeconomic position. In fact, a number of studies have shown that members of so-called "majority populations" could be more vulnerable to discrimination, since they are not as accustomed to discrimination as minorities are $[6,7]$.

Particularly in countries with collectivistic cultures such as Japan and Korea, members of the general community are not in the "discrimination safety zone." Previous studies have shown that up to $40 \%$ of Korean adolescents, especially those with low socioeconomic status or poor academic achievement, were involved in bullying, either as bullies or as victims $[8,9]$, suggesting that unjust treatment towards colleagues is rather ubiquitous among Korean adolescents. Adolescents are not the only subjects of unfair treatment; the Korean Working Conditions Survey, a nationwide survey conducted to evaluate the working conditions and health status of Korean workers, reported that $7.2 \%$ of workers had experienced unfair treatment at their workplace over the past 12 months [10].

A number of previous studies have also indicated that the negative health effects of discrimination could be moderated by social support $[4,11]$. However, effect modification by social support might be different in Asian populations due to cultural differences [12]. Additionally, evidences have suggested that there are gender differences in social support [13]. In this study, we examined the effects of discrimination on mental health in Korean general population and effect modification by social support to determine whether the results from previous studies could also be applied to the Korean population. Additionally, we attempted to investigate gender differences in social support by stratifying the study population according to gender and estimating the effect modification by social support in each gender group.

\section{METHODS}

\section{Participants}

This study is a cross-sectional study utilizing data from the third wave of the Jangseong High School Cohort (JS Cohort) study. The JS Cohort study is an ongoing prospective cohort study of Korean adolescents. In 2007, first-year students of Jangseong High School, which is located in a rural community of Korea, were recruited as participants. Among 1115 first-year students, 1071 students provided informed consent and participated in the first wave of the study. Participants were examined 3 times: in the first wave when they were 10th-graders, in the second wave 30 months after the first wave, and in the third wave from 2015 to 2019. Of the 1071 participants, 884 $(82.5 \%)$ completed the second wave of the study [14]. Systematically organized questionnaires assayed participants' psychological traits, including perceived discrimination and perceived social support, during the third wave of the study, and 412 complete responses to the psychological examinations were obtained. After excluding 40 participants with duplicate or missing data, 372 participants were included in this analysis.

\section{Independent Variable: Perceived Discrimination}

Perceived discrimination was assessed by the Everyday Discrimination Scale (EDS) in the third wave of the study. The EDS consists of 9 items that measure day-to-day discrimination, and is more frequently used in research than its alternatives $[15,16]$. Each item was rated on a 4-point Likert scale. Previous studies reported good validity of the EDS among Asian populations [17]. Particularly, a study on Korean-Americans showed that the EDS had high validity, with a Cronbach's $\alpha$ value of 0.87 [18]. The EDS scores had high internal consistency in our study, with Cronbach's $\alpha$ values of 0.89 in men and 0.86 in women.

\section{Dependent Variable: Depressive Symptoms}

We used the Beck Depression Inventory-II (BDI-II) to assess depressive symptoms in the third wave of the study. The BDI-II is a widely used questionnaire for assessing depressive symptoms [19]. Each item asks respondents to rate the severity of depressive symptoms, with responses ranging from 0 (none) to 3 (severe). The validity of the BDI-II among adolescents was measured in a meta-analysis of several studies conducted in multiple nations [20]. Additionally, researchers have validated the use of the BDI-II among Korean adolescents, with a Cronbach's $\alpha$ value of 0.89 [21]. The BDI-II scores obtained in our study had high internal consistency, with Cronbach's $\alpha$ values of 0.92 in men and 0.87 in women.

\section{Effect Modifier: Perceived Social Support}

Perceived social support was assessed by the Multidimensional Scale of Perceived Social Support (MSPSS) questionnaire in the third wave of the study. The MSPSS is a brief measure of perceived social support that consists of 3 domains with 4 questions each: family members, friends, and meaningful others. Herein, we present the original MSPSS questionnaire and its Korean version, which was used in this study (Supplemental Material 1). Each item is rated on a 5-point Likert scale. 
The MSPSS was originally validated in Western populations, but it has also been suggested that the MSPSS is useful for assessing social support in the Korean population [22]. The MSPSS scores calculated in our study had high internal consistency, with Cronbach's a values of 0.93 in men and 0.94 in women.

\section{Covariates}

Age, household income, and body mass index (BMI) were included as covariates. Information for household income was acquired during the first wave. Household income was measured as a categorical variable (million Korean won [KRW]/ mo). We compared the household income of our participants and those of participants in the Community Health Survey 2008 from Jangseong County, and our participants had significantly higher levels of income than the broader community population [23] (Supplemental Material 2). The national mean household income was $3369673 \mathrm{KRW} / \mathrm{mo}$ in 2008, so the household income of our participants was also somewhat higher than the national mean [24]. Since the income level of our participants was high and relatively homogeneous (Supplemental Material 2), we applied 3 million KRW/mo and 5 million KRW/mo as cut-off values to maintain the size of subgroups and the stability of the regression model. Participants without information on household income were categorized into a separate subgroup.

\section{Data Analyses}

Descriptive analyses were conducted to investigate the demographic characteristics of participants. Multivariate linear regression analyses were conducted after controlling for sociodemographic factors. Interactions between perceived discrimination and social support were tested by adding a linear interaction term between the total EDS scores (continuous) and the total MSPSS scores (continuous) to the model. We also conducted a post-hoc analysis to investigate the interaction between gender and discrimination.

We stratified participants by social support to investigate effect modification of social support. Zimet et al. [25], the developer of the MSPSS scale, suggested that as there are no established population norms for the MSPSS due to cultural and national variations, stratification either by representative values or by absolute scale response descriptor is feasible. Stratification by representative values of participants was used in several previous related studies of Asian young adults, including Korean medical students $[26,27]$. In particular, a study of Chi- nese undergraduate students stratified participants using mean MSPSS scores and discovered that social support moderated the association between stress and depressive symptoms [27]. Since our study population reported a relatively high degree of social support, we used the median value of the MSPSS scores (48 points) as a cut-off value for stratification. As the MSPSS consists of 3 domains, we also analyzed effect modification by each domain of MSPSS. In these analyses, we constructed parsimonious models by excluding household income to avoid instability of the regression model.

We investigated the correlation between social support and covariates by bivariate analyses to exclude possible biases in measuring the effect modification, and no covariates were significantly associated with social support. We also tested the collinearity of independent variables by obtaining variance inflation factor (VIF) values. We ensured that all VIF values were lower than 3.0 and concluded that multicollinearity between independent variables was acceptable. All statistical analyses were done using SAS version 9.4 (SAS Institute Inc., Cary, NC, USA).

\section{Ethics Statement}

The Institutional Review Board of Yonsei University has approved the use of JS Cohort data for research purposes (approval No. 4-2016-0273). All procedures contributing to this work complied with the ethical standards of the relevant national and institutional committees on human experimentation and with the Helsinki Declaration of 1975, as revised in 2008.

\section{RESULTS}

\section{Characteristics of Participants}

The mean and standard error (standard deviation [SD]) of the BDI-II scores were 7.1 (SD, 6.0) in men and $9.9(S D, 8.0)$ in women. The analysis of participants' discriminatory experiences showed that they were relatively frequently exposed to "impolite treatments," such as "being treated with less courtesy than others" and "receiving poorer services than others in restaurants or stores," but some reported experiences of "verbal aggressions" such as "being threatened or harassed," which are more aggressive types of discrimination (Supplemental Material 3). Women reported more discrimination than men did $(p<0.05)$. The mean and SD of the MSPSS scores were 48.7 (SD, 7.6) in men and $47.8(S D, 9.0)$ in women; 79 men and 114 wom- 
Table 1. Demographic characteristics of selected participants in the JS Cohort

\begin{tabular}{|c|c|c|c|}
\hline Characteristics & $\begin{array}{c}\text { Men } \\
(n=154)\end{array}$ & $\begin{array}{l}\text { Women } \\
(\mathrm{n}=\mathbf{2 1 8})\end{array}$ & $p$-value \\
\hline Age & $24.0 \pm 1.8$ & $23.7 \pm 1.7$ & 0.081 \\
\hline Household income $\left(10^{6}\right.$ Koren won/mo) & & & 0.527 \\
\hline $\operatorname{Low}(<3)$ & $25(16.2)$ & $31(14.2)$ & \\
\hline Mid (3-5) & $48(31.2)$ & $83(38.1)$ & \\
\hline $\operatorname{High}(>5)$ & $40(26.0)$ & $27(21.6)$ & \\
\hline $\mathrm{N} / \mathrm{A}$ & $41(26.6)$ & $57(26.1)$ & \\
\hline Drinking & & & $<0.001$ \\
\hline No & $118(76.6)$ & $209(95.9)$ & \\
\hline Yes & $36(23.4)$ & $9(4.1)$ & \\
\hline Smoking & & & 0.002 \\
\hline No & $145(94.2)$ & $217(99.5)$ & \\
\hline Yes & $9(5.8)$ & $1(0.5)$ & \\
\hline BMI $\left(\mathrm{kg} / \mathrm{m}^{2}\right)$ & & & 0.007 \\
\hline Underweight ( $\leq 18.4$ ) & $19(12.3)$ & $24(11.0)$ & \\
\hline Normal (18.5-22.9) & $77(50.0)$ & $147(67.4)$ & \\
\hline Overweight (23.0-24.9) & $33(21.4)$ & $25(11.5)$ & \\
\hline Obese $(\geq 25.0)$ & $25(16.3)$ & $22(10.1)$ & \\
\hline Ethnicity - Asian/Korean & $154(100)$ & $218(100)$ & - \\
\hline BDI-II scores & $7.1 \pm 6.0$ & $9.9 \pm 8.0$ & 0.042 \\
\hline EDS scores & $11.9 \pm 3.3$ & $13.4 \pm 4.0$ & 0.046 \\
\hline $\operatorname{Low}(9-10)$ & $67(43.5)$ & $57(26.1)$ & \\
\hline Mid (11-13) & 39 (25.3) & 80 (36.7) & \\
\hline High ( $\geq 14)$ & 48 (31.2) & 81 (37.2) & \\
\hline MSPSS scores & $48.7 \pm 7.6$ & $47.8 \pm 9.0$ & 0.335 \\
\hline $\operatorname{Low}(\leq 48)$ & $79(51.3)$ & $114(52.3)$ & \\
\hline $\operatorname{High}(\geq 49)$ & $75(48.7)$ & 104 (47.7) & \\
\hline
\end{tabular}

Values are presented as number (\%) or mean \pm standard deviation. JS Cohort, Jangseong High School Cohort; BMI, body mass index; BDI-II, Beck Depression Inventory-II; EDS, Everyday Discrimination Scale; MSPSS, Multidimensional Scale of Perceived Social Support; N/A, not applicable.

en received low social support, and 75 men and 104 women received high social support. There were no significant difference in the MSPSS score between men and women $(p=0.335)$ (Table 1).

\section{Associations Between Perceived Discrimination and Depressive Symptoms}

After adjusting for demographic factors and social support, a statistically significant positive association was found between perceived discrimination and depressive symptoms $(\beta=0.736, p<0.001)$ (Table 2$)$. The association was stronger in men $(\beta=1.158, p<0.001)$ than in women $(\beta=0.508, p<0.001)$ (Table 2).

\section{Effect Modification of Social Support: Overall Model}

A statistically significant negative association was found between social support and depressive symptoms $(\beta=-0.245$, $p<0.001)$. In the post-hoc analysis by gender, the association was significant in women $(\beta=-0.292, p<0.001)$ but not in men $(\beta=-0.068, p=0.272)$. The interaction between perceived discrimination and social support was also significant in women $(\beta=-0.030, p=0.001)$ but not in men $(\beta=-0.011, p=0.371)$ (Table 2).

A consistent positive association between perceived discrimination and depressive symptoms was detected in the stratified analyses, but the association was attenuated in the high-support subgroup $(\beta=0.382, p<0.001)$ compared to the low-support subgroup $(\beta=1.006, p<0.001)$. This attenuation was found in both men and women, but the differences in the regression coefficients between subgroups were greater in women (Table 3).

\section{Effect Modification of Social Support: Domain Model}

In men, only support from friends was negatively associated with depressive symptoms $(\beta=-0.631, p=0.011)$. There was no significant interaction between perceived discrimination and support from friends ( $\beta=-0.037, p=0.115$ ) (Table 2$)$. In contrast, family support was the only significant factor in women ( $\beta=-0.440, p=0.010$ ), and the interaction between perceived discrimination and family support was significant $(\beta=-0.085$, $p<0.001$ ) (Table 2).

Stratification by MSPSS domains with significant effects also yielded similar results. In men, although support from friends showed significant negative associations with depressive symptoms, the association between perceived discrimination and depressive symptoms did not differ according to support from friends (low subgroup: $\beta=1.129, p<0.001$; high subgroup: $\beta=1.350, p<0.001$ ) (Table 4). In contrast, women with higher family support showed a significantly diminished association between perceived discrimination and depressive symptoms ( $\beta=0.151, p=0.208)$ unlike those with lower family support $(\beta=0.917, p<0.001)$ (Table 4 ).

\section{DISCUSSION}

Perceived discrimination was positively associated with depressive symptoms in Korean young adults, and the associa- 


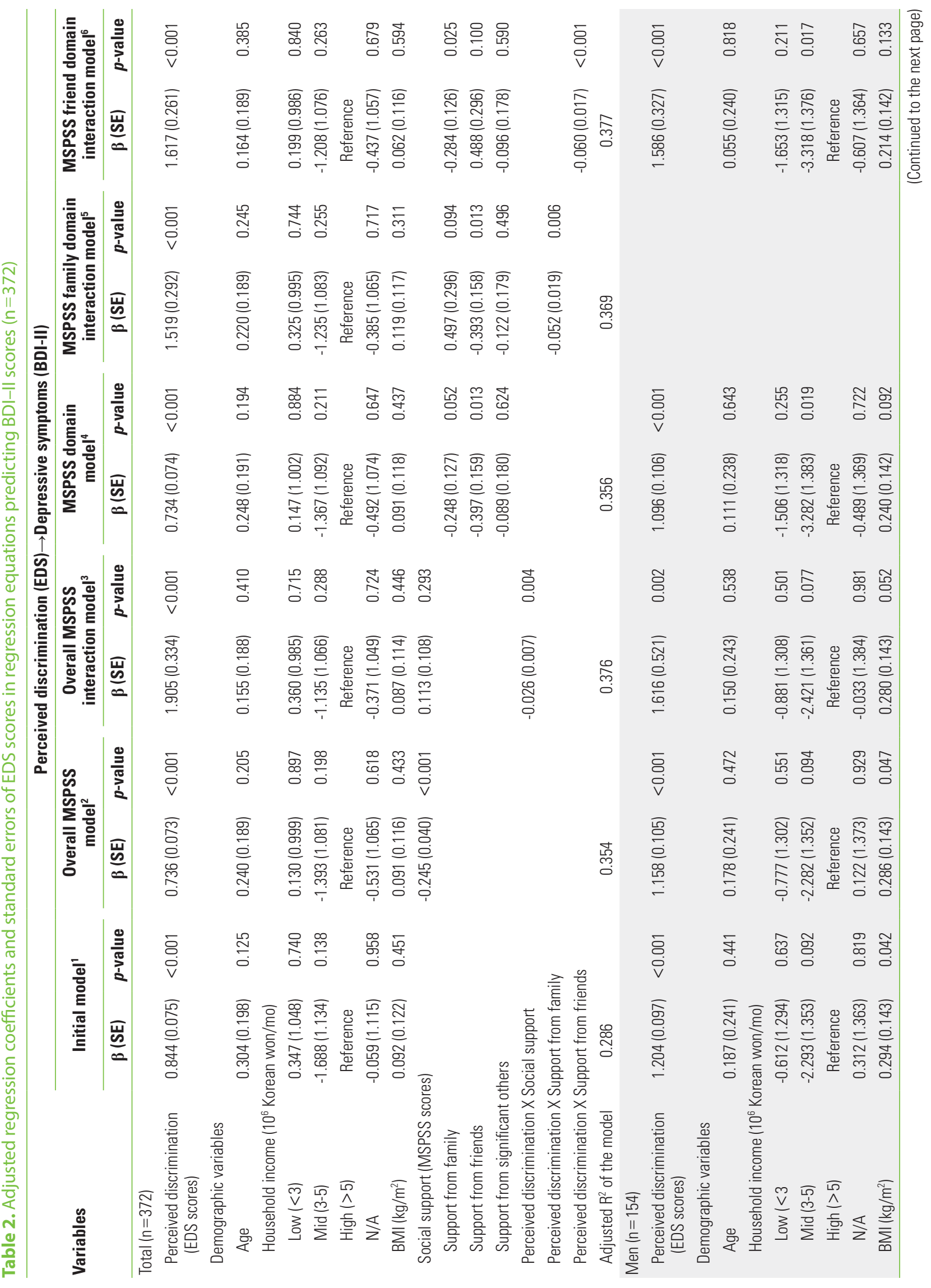




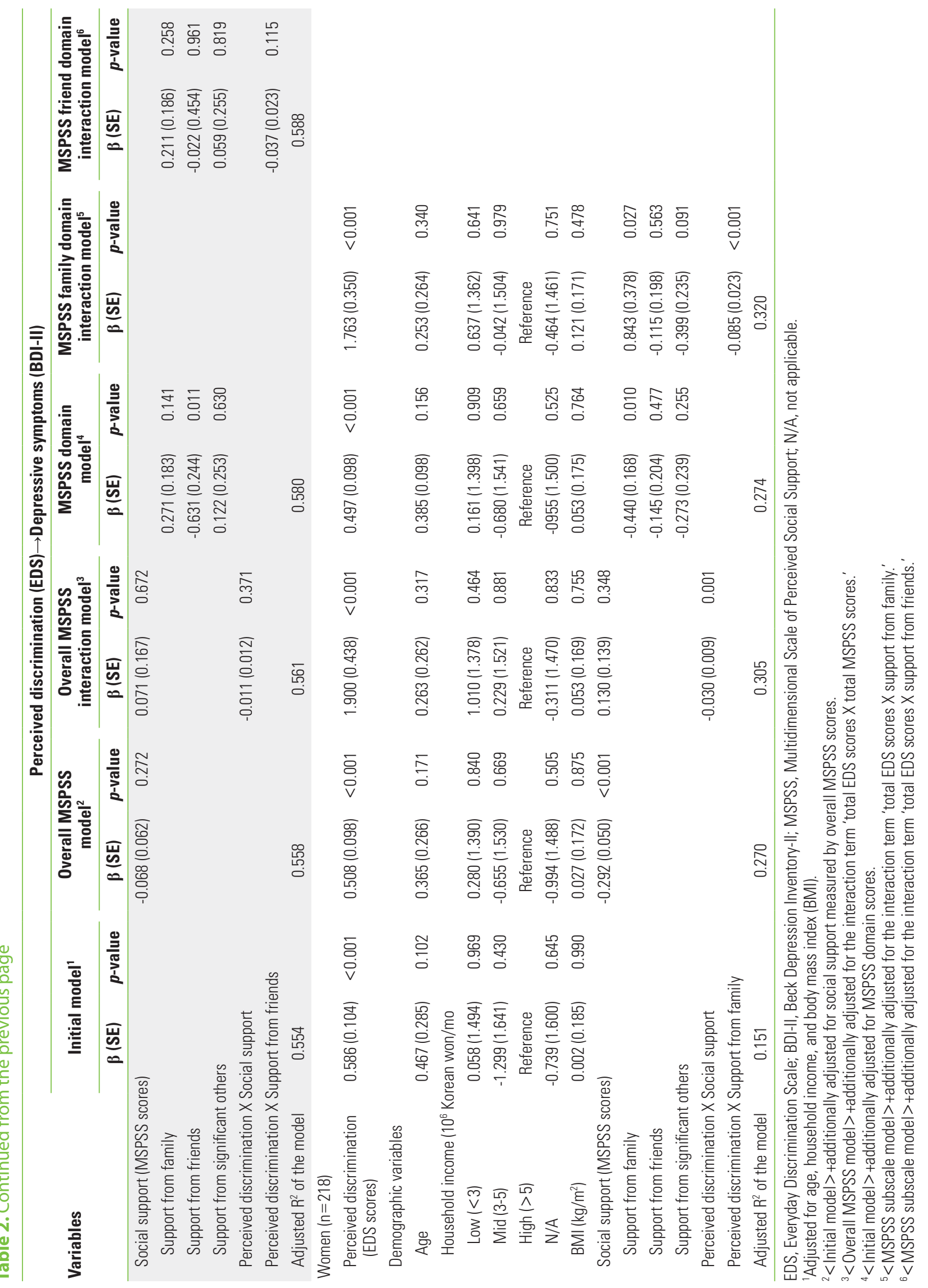


Table 3. Adjusted regression coefficients and standard errors of EDS scores in regression equations predicting BDI-II scores, stratified by total MSPSS scores

\begin{tabular}{|c|c|c|c|c|c|}
\hline \multirow{3}{*}{ Variables } & \multirow{3}{*}{$\mathbf{n}$} & \multicolumn{4}{|c|}{ Perceived discrimination (EDS) $\rightarrow$ Depressive symptoms (BDI-II) ${ }^{1}$} \\
\hline & & \multicolumn{2}{|c|}{ Low social support (MSPSS < 49) } & \multicolumn{2}{|c|}{ High social support (MSPSS $\geq 49$ ) } \\
\hline & & $\beta$ (SE) & $p$-value & $\beta$ (SE) & $p$-value \\
\hline Total (n) & 372 & 193 & & 179 & \\
\hline Perceived discrimination (EDS scores) & & $1.006(0.104)$ & $<0.001$ & $0.382(0.107)$ & $<0.001$ \\
\hline \multicolumn{6}{|l|}{ Demographic variables } \\
\hline Age & & $0.520(0.291)$ & 0.076 & $-0.312(0.252)$ & 0.218 \\
\hline \multicolumn{6}{|l|}{ Household income $\left(10^{6}\right.$ Korean won/mo) } \\
\hline $\operatorname{Low}(<3)$ & & $2.247(1.541)$ & 0.147 & $-1.701(1.272)$ & 0.183 \\
\hline Mid (3-5) & & $0.021(1.792)$ & 0.991 & $-2.593(1.295)$ & 0.047 \\
\hline $\operatorname{High}(>5)$ & & Reference & & Reference & \\
\hline $\mathrm{N} / \mathrm{A}$ & & $1.781(1.660)$ & 0.285 & $-2.203(1.340)$ & 0.102 \\
\hline $\mathrm{BMI}\left(\mathrm{kg} / \mathrm{m}^{2}\right)$ & & $0.067(0.170)$ & 0.700 & $0.137(0.163)$ & 0.400 \\
\hline $\operatorname{Men}(n)$ & 154 & 79 & & 75 & \\
\hline Perceived discrimination (EDS scores) & & $1.256(0.121)$ & $<0.001$ & $0.952(0.220)$ & $<0.001$ \\
\hline \multicolumn{6}{|l|}{ Demographic variables } \\
\hline Age & & $0.481(0.358)$ & 0.183 & $-0.223(0.328)$ & 0.498 \\
\hline \multicolumn{6}{|l|}{ Household income $\left(10^{6}\right.$ Korean won/mo) } \\
\hline $\operatorname{Low}(<3)$ & & $0.019(2.003)$ & 0.992 & $-2.002(1.756)$ & 0.258 \\
\hline Mid (3-5) & & $-2.488(2.178)$ & 0.257 & $-2.868(1.768)$ & 0.098 \\
\hline $\operatorname{High}(>5)$ & & Reference & & Reference & \\
\hline N/A & & $1.390(2.155)$ & 0.521 & $-0.916(1.768)$ & 0.606 \\
\hline $\mathrm{BMI}\left(\mathrm{kg} / \mathrm{m}^{2}\right)$ & & $0.471(0.194)$ & 0.018 & $-0.043(0.225)$ & 0.850 \\
\hline Women (n) & 218 & 114 & & 104 & \\
\hline Perceived discrimination (EDS scores) & & $0.821(0.159)$ & $<0.001$ & $0.150(0.130)$ & 0.254 \\
\hline \multicolumn{6}{|l|}{ Demographic variables } \\
\hline Age & & $0.688(0.409)$ & 0.095 & $-0.465(0.370)$ & 0.212 \\
\hline \multicolumn{6}{|l|}{ Household income $\left(10^{6}\right.$ Korean won/mo) } \\
\hline $\operatorname{Low}(<3)$ & & $2.378(2.189)$ & 0.280 & $-0.932(1.838)$ & 0.613 \\
\hline Mid (3-5) & & $1.605(2.581)$ & 0.536 & $-1.041(1.919)$ & 0.589 \\
\hline $\operatorname{High}(>5)$ & & Reference & & Reference & \\
\hline $\mathrm{N} / \mathrm{A}$ & & $1.036(2.314)$ & 0.655 & $-1.979(1.963)$ & 0.316 \\
\hline $\mathrm{BMI}\left(\mathrm{kg} / \mathrm{m}^{2}\right)$ & & $-0.128(0.273)$ & 0.639 & $0.288(0.225)$ & 0.203 \\
\hline
\end{tabular}

EDS, Everyday Discrimination Scale; BDI-II, Beck Depression Inventory-II; MSPSS, Multidimensional Scale of Perceived Social Support; BMI, body mass index.

${ }^{1}$ All models were adjusted for age, household income, and BMI.

tion was stronger if participants received lower social support. Such results indicate that social support could moderate the negative health effects of perceived discrimination.

However, the health effects of discrimination and social support varied by gender. The association between discrimination and depressive symptoms was stronger in men, indicating that men are more vulnerable to discrimination than women. The adjusted $R^{2}$ for the model adjusted for age, household income, and BMI (model A, Table 2) also presented stronger model fit in man participants (men: 0.554; women: 0.151), and a stronger influence of discrimination on depressive symptoms in men. In contrast, the effect modification by social support was stronger in women. Differences in the regression coefficients of social support, changes in the adjusted $R^{2}$ value after adjusting for the MSPSS scores (men: $0.554 \rightarrow 0.558$; women: $0.151 \rightarrow 0.270$ ) (Table 2 ), and the results of the stratified analyses suggested that the effect modification by social support could be beneficial in both genders, but more so in women.

Few studies have tested the health effects of discrimination in Korean population, and most such studies have primarily 
Table 4. Adjusted regression coefficients and standard errors of EDS scores in regression equations predicting BDI-II scores, stratified by significant MSPSS domain scores

\begin{tabular}{|c|c|c|c|c|c|c|c|c|}
\hline \multirow[b]{3}{*}{ Variables } & \multicolumn{8}{|c|}{ Perceived discrimination (EDS) $\rightarrow$ Depressive symptoms (BDI-II) ${ }^{1}$} \\
\hline & \multicolumn{4}{|c|}{ Men $(n=154)$} & \multicolumn{4}{|c|}{ Women (n=218) } \\
\hline & $\begin{array}{c}\text { Low (friend } \\
\text { support }<16 \text {, } \\
n=51 \text { ) }\end{array}$ & $p$-value & $\begin{array}{l}\text { High (friend } \\
\text { support } \geq 16 \text {, } \\
n=103 \text { ) }\end{array}$ & $p$-value & $\begin{array}{c}\text { Low (family } \\
\text { support }<16 \text {, } \\
n=89 \text { ) }\end{array}$ & $p$-value & $\begin{array}{l}\text { High (family } \\
\text { support } \geq 16 \text {, } \\
n=129 \text { ) }\end{array}$ & $p$-value \\
\hline $\begin{array}{l}\text { Perceived discrimination } \\
\text { (EDS scores) }\end{array}$ & $1.129(0.143)$ & $<0.001$ & $1.350(0.179)$ & $<0.001$ & $0.917(0.156)$ & $<0.001$ & $0.151(0.119)$ & 0.208 \\
\hline \multicolumn{9}{|l|}{ Demographic variables } \\
\hline Age & $-0.002(0.490)$ & 0.996 & $0.206(0.251)$ & 0.414 & $0.904(0.493)$ & 0.070 & $0.158(0.288)$ & 0.583 \\
\hline $\mathrm{BMI}\left(\mathrm{kg} / \mathrm{m}^{2}\right)$ & $0.945(0.257)$ & $<0.001$ & $-0.123(0.163)$ & 0.450 & $-0.464(0.306)$ & 0.133 & $0.274(0.194)$ & 0.161 \\
\hline
\end{tabular}

Values are presented as $\beta$ (standard error).

EDS, Everyday Discrimination Scale; BDI-II, Beck Depression Inventory-II; MSPSS, Multidimensional Scale of Perceived Social Support; BMI, body mass index. ${ }^{1}$ All models were adjusted for age and BMI.

focused on elderly populations [28]. However, previous studies have shown that young Korean adults with low socioeconomic status or poor academic achievements could experience discrimination $[8,9]$. To address this knowledge gap, we investigated the effects of discrimination on depression and moderation by social support in Korean young adults. Additionally, we explored gender differences in the impacts of discrimination and social support in the general population.

Our results suggest that the association between perceived discrimination and mental health is strong in Korean young adults, consistent with previous studies conducted in various ethnic groups $[2,29]$. As the participants of our study were ethnic non-minority Koreans, most of them rarely experienced discrimination, and they reported a low degree of depressive symptoms. However, some of them reported a higher level of perceived discrimination and depressive symptoms than other participants. The regression coefficient of perceived discrimination on depression $(\beta=0.736)$ suggests that non-minority individuals are not "safe" from discrimination and its negative effects on mental health, even though their baseline levels of depression and perceived discrimination are relatively low.

Since there could be cultural differences in the health effects of discrimination and social support [12], results from Western populations cannot be directly applied to Asian populations with different cultural backgrounds. The ethnic and cultural homogeneity of the JS Cohort population could be helpful for understanding the health effects of discrimination and social support among Asian populations with high ethnic homogeneity.

Our results imply that the impact of discrimination on mental health is larger in men. A post-hoc analysis revealed a sig- nificant interaction between gender and discrimination (men as reference group, $\beta=-0.574, p<0.001$ ). A similar study on immigrants implied that Iranian and Korean men are more vulnerable to discrimination-related depressive symptoms than their woman counterparts [17]. Kim and Noh [17] suggested that emotional reactions towards discrimination, such as anger and sadness, are more intense in Korean men immigrants, resulting in worse mental health effects. Furthermore, differences in the frequency and intensity of discrimination causes differences in resilience [30]. In our study, woman participants reported a higher level of perceived discrimination, so it could be hypothesized that they developed resilience towards discrimination.

It is also notable that among Irish, Ethiopian, and Vietnamese immigrants, women were found to be more vulnerable to discrimination, unlike Korean and Iranian immigrants [30]. According to Cokley et al. [31], differences in coping mechanisms towards discrimination result in different health effects. This implies that results from different ethnic groups could not be directly applied to the Korean population, and that more research on the Korean population is needed to understand the role of discrimination in health.

The analysis presented in this study indicates that the association between perceived discrimination and depressive symptoms could be moderated by social support, implying that social support has a protective effect against discrimination. Interpersonal influences on emotional regulation are a mechanism through which social support acts on depressive symptomatology [32]. Social support provides an interpersonal level of cognitive and emotional regulation, preventing depressive symptoms from developing further and diminishing 
former symptoms through cognitive changes and attentional deployment [32]. Our results suggest that social support could moderate the negative health effects of discrimination, and providing social support could be a measure to prevent depression in non-minority individuals.

In our study, women received greater health benefits from social support than men. It has been consistently suggested that the health effects of social support are more beneficial in women [22,23], since women have evolved to adapt befriending as a major mechanism to fight against stress [33], which allows them to utilize social support to reduce stress and reobtain emotional regulation [32]. Several previous studies have shown gender differences in social support $[29,33]$, supporting the implications of this study.

Support from friends was the most important domain in men, while family support was the most influential factor in women. According to Chopik [34], friendship becomes more important from the perspective of health and welfare as we age, but this does not explain why family support was the most influential factor in women. Since women are influenced more by family support [35], it could be postulated that the importance of support from friends grows earlier in men, becoming the most influential domain of social support in men.

Interestingly, BMI was positively associated with depressive symptoms in men, especially in those with low social support. The perception on ideal body image and its association with depression is highly culture-dependent; previous studies that analyzed body image in university students from 22 countries found that Asian young adults tended to overestimate their body shape, indicating that a lean body is perceived as ideal among Asian young adults [36]. Kim [37] suggested that body dissatisfaction is linked to suicidal ideation, and that social relations partially mediate this association. The results of our study are consistent with those of previous research [36,37], and it suggests that overweight/obese individuals are prone to be dissatisfied with their body shape, resulting in depression. Further studies on the ideal body shape and its association with depression in Korean young adults should be conducted to obtain a more comprehensive understanding.

We are aware of several limitations of our study. Since this is a cross-sectional study, we cannot infer causality from its results. To complement this limitation, follow-up evaluations for psychological traits are currently underway. With longitudinal data, it will become possible to infer causality in further studies by establishing a temporal relationship between discrimi- nation and depressive symptoms.

Generalization of our results may be challenging due to rural nature of the JS Cohort. A previous study conducted in China suggested that urban-born adolescents had better mental health and received higher social support [38], but the opposite was true in a Korean study [39]. Although the associations between urbanicity and psychosocial factors should be further investigated, the health effects of discrimination and social support might vary by urbanicity. Additionally, the relatively high socioeconomic status of our participants could affect psychosocial factors and their interactions, further hindering the generalizability of our findings $[8,23,24]$. A nationwide study with national-level psychosocial indicators could provide a more comprehensive understanding of the health role of discrimination and social support. However, this demographic characteristic could yield advantages as well; the participants were relatively homogeneous and were mostly free from comorbidities, so confounding effects attributable to comorbidities were attenuated.

A significant proportion of participants were excluded because they did not complete the psychological examination. Although the baseline characteristics of the participants included in and excluded from this study were not significantly different, this might also be a source of bias.

Covariates measured in the first wave were utilized as surrogate variables to represent the current status of participants. Although the demographic variables included in this analysis are relatively non-time-dependent, differences between the first and third waves might have diminished the representativeness of the model. To minimize this concern, we excluded highly time-dependent lifestyle variables from our regression model.

Lastly, our measures of depressive symptoms were based on self-reported questionnaires, so reporting bias could have been present. For instance, depressed participants might have underestimated the social support they received, potentially resulting in a consequent overestimation of the association. However, we found a consistent direction of the association in the participants with high levels of social support, so the possibility of reporting bias is unlikely to alter the direction of the association.

Despite these limitations, this study could shed light on the role of discrimination and social support in the mental health of the Korean population. Although further studies are required to understand the health impacts of discrimination 
more accurately, we detected negative health impacts of discrimination in a Korean non-minority population. We also found that social support could be beneficial for community members experiencing discrimination, and that reactions towards discrimination and social support could vary by gender. Mental healthcare providers and community members should be aware of the negative health effects of discrimination, especially for members without sufficient social support.

\section{SUPPLEMENTAL MATERIALS}

Supplemental materials are available at https://doi.org/10. 3961/jpmph.19.114.

\section{CONFLICT OF INTEREST}

The authors have no conflicts of interest associated with the material presented in this paper.

\section{ACKNOWLEDGEMENTS}

We would like to thank every member of the JS Cohort research team who constructed the JS Cohort, helped us design this study, and gave us feedback on our articles.

This study was supported by a National Research Foundation of Korea (NRF) grant funded by the Ministry of Science and ICT (NRF-2018R1C1B5083722).

\section{AUTHOR CONTRIBUTIONS}

Conceptualization: KK, SJJ. Data curation: SMJC, JHP, HCK. Formal analysis: KK. Funding acquisition: SJJ. Methodology: KK, SJJ. Project administration: HCK, SJJ, JHP. Visualization: KK, SJJ. Writing - original draft: KK. Writing - review \& editing: KK, SJJ, SMJC, JHP, HCK.

\section{ORCID}

Kwanghyun Kim https://orcid.org/0000-0001-9552-5085

Sun Jae Jung https://orcid.org/0000-0002-5194-7339

So Mi Jemma Cho https://orcid.org/0000-0003-2460-3335

Ji Hye Park https://orcid.org/0000-0002-1004-2496

Hyeon Chang Kim https://orcid.org/0000-0001-7867-1240

\section{REFERENCES}

1. Stepanikova I, Baker EH, Simoni ZR, Zhu A, Rutland SB, Sims M, et al. The role of perceived discrimination in obesity among African Americans. Am J Prev Med 2017;52(1S1):S77-S85.

2. Wickham S, Taylor P, Shevlin M, Bentall RP. The impact of social deprivation on paranoia, hallucinations, mania and depression: the role of discrimination social support, stress and trust. PLoS One 2014;9(8):e105140.

3. Gilman SE, Bruce ML, Ten Have T, Alexopoulos GS, Mulsant BH, Reynolds CF 3rd, et al. Social inequalities in depression and suicidal ideation among older primary care patients. Soc Psychiatry Psychiatr Epidemiol 2013;48(1):59-69.

4. Chou KL. Perceived discrimination and depression among new migrants to Hong Kong: the moderating role of social support and neighborhood collective efficacy. J Affect Disord 2012; 138(1-2):63-70.

5. Gee GC, Ro A, Shariff-Marco S, Chae D. Racial discrimination and health among Asian Americans: evidence, assessment, and directions for future research. Epidemiol Rev 2009;31: 130-151.

6. Lee JH, Gamarel KE, Bryant KJ, Zaller ND, Operario D. Discrimination, mental health, and substance use disorders among sexual minority populations. LGBT Health 2016;3(4):258-265.

7. Williams DR, Collins C. US socioeconomic and racial differences in health: patterns and explanations. Annu Rev Sociol 1995; 21(1):349-386.

8. Kim YS, Koh YJ, Leventhal B. School bullying and suicidal risk in Korean middle school students. Pediatrics 2005;115(2):357363.

9. Koo H, Kwak K, Smith PK. Victimization in Korean schools: the nature, incidence, and distinctive features of Korean bullying or wang-ta. J Sch Violence 2008;7(4):119-139.

10. Min JY, Park SG, Kim SS, Min KB. Workplace injustice and selfreported disease and absenteeism in South Korea. Am J Ind Med 2014;57(1):87-96.

11. Rodriguez CJ, Gwathmey TM, Jin Z, Schwartz J, Beech BM, Sacco RL, et al. Perceived discrimination and nocturnal blood pressure dipping among Hispanics: the influence of social support and race. Psychosom Med 2016;78(7):841-850.

12. Kim HS, Sherman DK, Taylor SE. Culture and social support. Am Psychol 2008;63(6):518-526.

13. Belle D. Gender differences in the social moderators of stress. In: Monat A, Lazarus RS, editors. Stress and coping: an anthology. New York: Columbia University Press; 1991, p. 257-277. 
14. Choi DP, Lee JY, Kim HC. Cohort profile: the JS high school study (JSHS): a cohort study of Korean adolescents. Int J Epidemiol 2017;46(2):393-402.

15. Krieger N. Methods for the scientific study of discrimination and health: an ecosocial approach. Am J Public Health 2012; 102(5):936-944.

16. Ajrouch KJ, Reisine S, Lim S, Sohn W, Ismail A. Perceived everyday discrimination and psychological distress: does social support matter? Ethn Health 2010;15(4):417-434.

17. Kim IH, Noh S. Ethnic and gender differences in the association between discrimination and depressive symptoms among five immigrant groups. J Immigr Minor Health 2014;16(6): 1167-1175.

18. Jang Y, Chiriboga DA, Kim G, Rhew S. Perceived discrimination in older Korean Americans. Asian Am J Psychol 2010;1(2):129135.

19. Beck AT, Steer RA, Brown GK. BDI-II: beck depression inventory. 2nd ed. San Antonio: Psychological Corp.; 1996, p. 490-498.

20. Stockings E, Degenhardt L, Lee YY, Mihalopoulos C, Liu A, Hobbs $M$, et al. Symptom screening scales for detecting major depressive disorder in children and adolescents: a systematic review and meta-analysis of reliability, validity and diagnostic utility. J Affect Disord 2015;174:447-463.

21. Lee EH, Lee SJ, Hwang ST, Hong SH, Kim JH. Reliability and validity of the beck depression inventory-II among Korean adolescents. Psychiatry Investig 2017;4(1):30-36.

22. Park $H$, Nguyen T, Park H. Validation of multidimensional scale of perceived social support in middle-aged Korean women with diabetes. Asia Pac J Soc Work Dev 2012;22(3):202-213.

23. Korean Centers for Disease Control and Prevention. Community Health Survey; 2008 [cited 2019 Nov 19]. Available from: https://chs.cdc.go.kr/chs/mnl/mnlBoardMain.do (Korean).

24. Korean Statistical Information Service. Average monthly expenditure by income decile; 2019 [cited 2019 Nov 10]. Available from: http://kosis.kr/statisticsList/statisticsListlndex.do? me-nuld=M_01_01\&vwcd=MT_ZTITLE\&parmTabld = M_01_ 01\&statld = 1962009\&themald = C\#SelectStatsBoxDiv (Korean).

25. Zimet GD, Dahlem NW, Zimet SG, Farley GK. The multidimensional scale of perceived social support. J Pers Assess 1988; 52(1):30-41.

26. Hwang IC, Park KH, Kim JJ, Yim J, Ko KP, Bae SM, et al. Perceived social support as a determinant of quality of life among medical students: 6-month follow-up study. Acad Psychiatry 2017; 41(2):180-184.

27. Wang X, Cai L, Qian J, Peng J. Social support moderates stress effects on depression. Int J Ment Health Syst 2014;8(1):41.

28. Lee HS, Kim C. Structural equation modeling to assess discrimination, stress, social support, and depression among the elderly women in South Korea. Asian Nurs Res (Korean Soc Nurs Sci) 2016;10(3):182-188.

29. Clark TT, Salas-Wright CP, Vaughn MG, Whitfield KE. Everyday discrimination and mood and substance use disorders: a latent profile analysis with African Americans and Caribbean Blacks. Addict Behav 2015;40:119-125.

30. Turner RJ, Avison WR. Status variations in stress exposure: implications for the interpretation of research on race, socioeconomic status, and gender. J Health Soc Behav 2003;44(4):488505.

31. Cokley K, Hall-Clark B, Hicks D. Ethnic minority-majority status and mental health: the mediating role of perceived discrimination. J Ment Health Couns 2011;33(3):243-263.

32. Marroquín B. Interpersonal emotion regulation as a mechanism of social support in depression. Clin Psychol Rev 2011; 31(8):1276-1290.

33. Taylor SE, Klein LC, Lewis BP, Gruenewald TL, Gurung RA, Updegraff JA. Biobehavioral responses to stress in females: tendand-befriend, not fight-or-flight. Psychol Rev 2000;107(3): 411-429.

34. Chopik WJ. Associations among relational values, support, health, and well-being across the adult lifespan. Pers Relatsh 2017;24(2):408-422.

35. Walen HR, Lachman ME. Social support and strain from partner, family, and friends: costs and benefits for men and women in adulthood. J Soc Pers Relat 2000;17(1):5-30.

36. Wardle J, Haase AM, Steptoe A. Body image and weight control in young adults: international comparisons in university students from 22 countries. Int J Obes (Lond) 2006;30(4):644651.

37. Kim DS. Body image dissatisfaction as an important contributor to suicidal ideation in Korean adolescents: gender difference and mediation of parent and peer relationships. J Psychosom Res 2009;66(4):297-303.

38. Zhang M, Zhang J, Zhang F, Zhang L, Feng D. Prevalence of psychological distress and the effects of resilience and perceived social support among Chinese college students: does gender make a difference? Psychiatry Res 2018;267:409-413.

39. Zhuang $X Y$, Wong DF. Differential impacts of social support on mental health: a comparison study of Chinese rural-to-urban migrant adolescents and their urban counterparts in Beijing, China. Int J Soc Psychiatry 2017;63(1):48-56. 